\title{
Silver Diamine Fluoride in Pediatric Dentistry
}

\author{
Sivakumar Nuvvula ${ }^{1}$, Sreekanth Kumar Mallineni ${ }^{2}$
}

\begin{abstract}
Dental caries remains a severe oral health problem in children and its impact in terms of pain, impairment of function, and oral health-related quality of life of the population is high, especially the disadvantaged individuals and communities. Despite the widespread use of fluoride dentifrice, preschool children, compared to the other age groups, still show a high number of untreated caries lesions. Minimal and noninvasive approaches for the management of dental caries are preferred currently, in lieu of the conventional approaches. Though not new, silver diamine fluoride (SDF) had recently gained attention by clinicians globally due to its effectiveness in arresting the progression of carious lesions. Silver diamine fluoride allows a more conservative tooth preparation as it has been shown to arrest remaining decay, remineralize, and harden leathery dentin leading to the dark color change. Silver diamine fluoride is applied directly to carious lesions to arrest and prevent dental caries. Since the management of dental caries with SDF is noninvasive and much comfortably performed, it can be a favorable means to treat dental caries in children. The present review is an insight into the use of SDF in pediatric dentistry and its clinical significance based on the published literature. Keywords: Caries arrest, Silver diamine fluoride, Silver modified atraumatic restorative technique.

Journal of South Asian Association of Pediatric Dentistry (2019): 10.5005/jp-journals-10077-3024
\end{abstract}

\section{INTRODUCTION}

Despite being a mostly preventable disease, dental caries remains a severe oral health problem in children. Its impact on individuals and population related to pain, diminished function, and oral healthrelated quality of life is high, especially the disadvantaged individuals and communities. 1 The widespread use of fluoride dentifrices resulted in a significant reduction in dental caries scores and considerable improvement in the oral health status of children. ${ }^{2}$ However, preschool children, compared to the other age groups, still show a high number of untreated caries lesions, and the decay component is the highest in the deft index. ${ }^{3,4}$ Children from low-income countries have their overall health, social well-being, as well as learning activities in school affected by untreated dental caries due to inadequate monetary resources, meager access to primary oral care, and the higher expenses for restorative dentistry. ${ }^{5}$ Dental fear, economic confines, scheduling difficulties, and conveyance issues are among the significant obstacles to dental care of children, as reported by parents. ${ }^{6}$

Conventionally, the management of the carious lesions follows surgical eradication of the carious tissue and the replacement with a suitable restorative material. ${ }^{7}$ Subsequently, minimal invasive dentistry (MID), which aims at maintenance of the sound tooth structure using noninvasive techniques, has replaced the conventional procedures. ${ }^{8}$ Treatments such as arresting the carious lesions can be delivered at the community level regularly to halt the progression of the carious lesion. ${ }^{9}$ Though not new, silver diamine fluoride (SDF) most recently had demonstrated amplified attention by clinicians globally due to its effectiveness in arresting the progression of carious lesions. ${ }^{10,11}$ More than four decades witnessed the successful usage of silver fluoride $(\mathrm{AgF})$ as a preventive material in both clinical and in vitro studies. ${ }^{12}$ The U.S. Food and Drug Administration (FDA) gave clearance in August 2014 to the first SDF preparation for dental use in the United States and is available for use since April 2015. Horst et al. opined that SDF makes its use in community dental health programs due to its low cost, and it was recommended for once or twice a year application of this as a preventive agent. ${ }^{13}$

According to Crystal and Niederman, various systematic reviews validate SDF's effectiveness for caries arrest and prevention
1,2Department of Pedodontics and Preventive Dentistry, Narayana
Dental College and Hospital, Nellore, Andhra Pradesh, India

Corresponding Author: Sivakumar Nuvvula, Department of Pedodontics and Preventive Dentistry, Narayana Dental College and Hospital, Nellore, Andhra Pradesh, India, Phone: +91 9441624429, e-mail: dentist4kids@gmail.com

How to cite this article: Nuvvula S, Mallineni SK. Silver Diamine Fluoride in Pediatric Dentistry. J South Asian Assoc Pediatr Dent 2019;2(2):73-80.

Source of support: Nil

Conflict of interest: None

in primary dentition and meets the US. Institute of Medicine's six quality aims. Silver diamine fluoride is safe, as there are no serious adverse events reported in the clinical trials conducted and published worldwide. Silver diamine fluoride is effective, as it arrests nearly $80 \%$ of the treated lesions. Silver diamine fluoride is efficient and can be applied with minimum training in less than 1 minute by health professionals in various health and community settings. Silver diamine fluoride can be timely due to its ease of application and utility as an intervention agent, the moment the problem is detected. Silver diamine fluoride is patient-centered and meets the instant needs of a child in one treatment session as it is minimally invasive and painless. Last, SDF is equitable as its application is practical and inexpensive, with one application costing less than \$1 (INR around 70); hence, it is a feasible option for low-income groups. ${ }^{14}$

The present review is an insight into the use of SDF in dentistry and its clinical significance based on the published literature.

\section{History Related to Silver Products in Dentistry}

The first mention of the medicinal usage of silver dates back to $1000 \mathrm{BC}$ or earlier, as water stored in silver vessels exposed to 
light, or filtered, was rendered potable and the antimicrobial properties of silver compounds are well documented. ${ }^{15}$ According to Stebbins, ${ }^{16}$ arresting of carious lesions by silver nitrate (silver amalgam and nitric acid) dates back to 1891, with about 87 of 142 treated lesions were arrested over 3 years. Stebbins postulated that caries reduction was due to antibacterial action and the deposition of a "black crust," producing a sclerotic protective layer of secondary dentin. Howe ${ }^{17}$ used ammoniacal silver nitrate solution on carious lesions that resulted in a black layer of sclerotic dentin, which appeared to arrest the development of future carious lesions. Howe's solution was popular up to the 1950s to sterilize the prepared caries lesions and as a disinfectant in root canal treatment; however, doubts of its clinical efficacy and possible adverse effects on the pulp were a concern. Some studies showed that silver nitrate appears to penetrate both sound and carious as well as vital and nonvital dentine with a mild, self-limiting, localized effect on the pulp. ${ }^{7}$ During the 1970s, AgF was introduced in Western Australia as a part of the minimal intervention for school dental services. ${ }^{18}$ Silver diamine fluoride was studied first by Nishino, as a part of a PhD thesis at Osaka University in Japan in 1969, conglomerating the potent antimicrobial properties of silver with the benefits of a high dose of fluoride. ${ }^{19}$ This formulation also resulted in a precipitate that occluded dentinal tubules and reduced hypersensitivity. Later on, "diammine silver fluoride" was approved by the Central Pharmaceutical Council of the Ministry of Health and Welfare of Japan as a cariostatic agent and was marketed as Saforide (Toyo Seiyaku Kasei Co. Ltd, Osaka, Japan). ${ }^{20}$ Several studies of SDF followed this as an alternative dental caries treatment in the developing countries, where access to oral health care is exceptionally limited. ${ }^{10,21}$

\section{Silver Diamine Fluoride}

Literature mentions SDF with various names since 1969, such as silver diammine fluoride, ammoniated silver fluoride, ammoniacal silver fluoride, silver fluoride diamine, diamine silver fluoride, silver diamine fluoride, and diammine silver fluoride. This SDF compound, $\mathrm{AgF}\left(\mathrm{NH}_{3}\right)$, is usually misinterpreted or misspelled as silver diamine fluoride, though the appropriate term is silver diammine fluoride containing two ammine groups $\left(\mathrm{NH}_{3}\right)$, not two amine groups $\left(\mathrm{NH}_{2}\right)$. The term "diamine" consequently became so universal, and it has been accepted from both the scientific and promotion platforms. ${ }^{7}$

\section{Composition of SDF}

In general, SDF solutions contain ammonia, silver, and fluoride. The fluoride content in SDF solutions varies from brand to brand. ${ }^{22}$ As available in the United States, SDF is a colorless topical agent (38\% $\mathrm{w} / \mathrm{v} \mathrm{Ag}\left(\mathrm{NH}_{3}\right)_{2} \mathrm{~F}, 30 \% \mathrm{w} / \mathrm{w}$ ) comprised of $24.4-28.8 \%(\mathrm{w} / \mathrm{v})$ silver and 5.0-5.9\% fluoride, at $\mathrm{pH} 10$, and marketed as Advantage Arrest by Elevate Oral Care, LLC, West Palm Beach, Florida. ${ }^{13}$ The composition may vary depending on the brands and the manufacturers. Table 1 presents some of the brands of SDF available. ${ }^{23-25}$

\section{Indications and Contraindications of SDF ${ }^{13,26-30}$}

The SDF is indicated in the following situations:

- Individuals with high caries risk with active cavitated lesions on any surface of the anterior or posterior primary teeth and permanent first molars

- Individuals with behavioral or medical management problems having cavitated dental caries lesions, when local or general anesthesia is not preferred or to be delayed to a later date as a holding measure until definitive treatment is possible, as in cases of precooperative children

- Individuals with several cavitated dental caries lesions, needing multiple visits to manage (cannot be managed in a single visit)

- Cavitated dental caries lesions that are difficult to treat

- Individuals or communities lacking access to or with difficulty in accessing dental care

- Active cavitated dental caries lesions without any clinical signs of pulp involvement

- As part of the silver modified atraumatic restorative technique (SMART)

- Treatment of dentinal hypersensitivity

- Treatment of molar incisor hypomineralization (MIH)

- Treatment of recurrent caries (secondary caries) at the restoration margins

- Treatment of incipient interproximal lesions

- Disinfection of the root canal system

- Indirect pulp treatment (IPT)

- Arresting caries to maintain the teeth nearing exfoliation

- As a substitute to sealants in children who cannot endure a scrupulous sealant procedure.

The SDF is contraindicated in the following situations:

- Individuals with known silver allergy

- Individuals with oral soft tissue ulcerations, especially that can come in contact during application of SDF

- Active cavitated caries lesions with pulp involvement as per the clinical judgment

- If parents/guardians do not consent for using SDF, along with concerns of the color change.

\section{Selection of Teeth for the Application of SDF ${ }^{13,26,27}$}

- Absence of clinical signs related to inflamed pulp or history of spontaneous pain

- Carious lesions that are not infringing on to the pulp. When possible, prescribe radiographs to assess the proximity of pulp to caries lesions

- Carious lesions on any surface that are accessible with a brush during SDF application

- Before placement of restoration and as a cariostatic means.

\section{Clinical Application Protocol of SDF ${ }^{13,26,27}$}

- Explain the procedure and possible adverse events that can occur with the application of SDF and obtain an informed written consent from the parent as well as an ascent from the child.

- Eliminate the plaque and other debris from the cavitated lesion.

- Removal of soft caries from the lesion before application of SDF may not be necessary or may be considered for esthetic purposes, and this may reduce the proportion of arrested caries that cause discoloration of the tooth.

- A protective coating of petroleum jelly may be used to avoid the possible, transitory henna-appearing tattoo that can occur if SDF comes into contact with to the skin and lips or other soft tissues.

- The areas to be treated are isolated with cotton rolls or alternative methods.

- Avoid inadvertent staining of the permanent anterior teeth that may have noncavitated (white spot) lesions that are in contact with the primary teeth during SDF application. 
Table 1: Commercially available brands that supply SDF ${ }^{24-26}$

\begin{tabular}{|c|c|c|c|c|c|}
\hline SDF (\%) & Product brand & Manufacturer & Country & Ingredients & Package \\
\hline 10 & Cariostatic & Inodon Laboratorio & Brazil & SDF & 5-mL dropper bottle \\
\hline 12 and 30 & Cariestop & Biodinamica & Brazil & $\begin{array}{l}\text { Fluoridic acid, silver nitrate, } \\
\text { ammonia }\end{array}$ & $\begin{array}{l}5-\mathrm{mL} \text { or } 10-\mathrm{mL} \text { dropper } \\
\text { bottle }\end{array}$ \\
\hline 30 & Bioride & Dentsply & Brazil & SDF & 5-mL dropper bottle \\
\hline 38 & Fluoroplat & NAF laboratorio & Argentina & SDF & 5-mL dropper bottle \\
\hline 38 & Saforide & Toyo Seiyaku Kasei & Japan & SDF & 5-mL dropper bottle \\
\hline 38 & Advantage Arrest & Elevate Oral Care & United States & SDF & 8-mL dropper bottle \\
\hline 38 & e-SDF & $\begin{array}{l}\text { Kids-e-dental, Mum- } \\
\text { bai }\end{array}$ & India & SDF & 5-mL dropper bottle \\
\hline 38 & FAgamin & Tedequim SRL & Argentina & SDF & 5-mL dropper bottle \\
\hline $30-35$ & Riva Star & SDI Dental Ltd & Australia & $\begin{array}{l}\text { Unit 1: silver, fluoride, ammonia; } \\
\text { unit 2: potassium, iodine, } \\
\text { methacrylates }\end{array}$ & $\begin{array}{l}\text { Unit 1: } 0.05 \mathrm{~mL} \text {; } \\
\text { unit 2: } 0.10 \mathrm{~mL}\end{array}$ \\
\hline
\end{tabular}

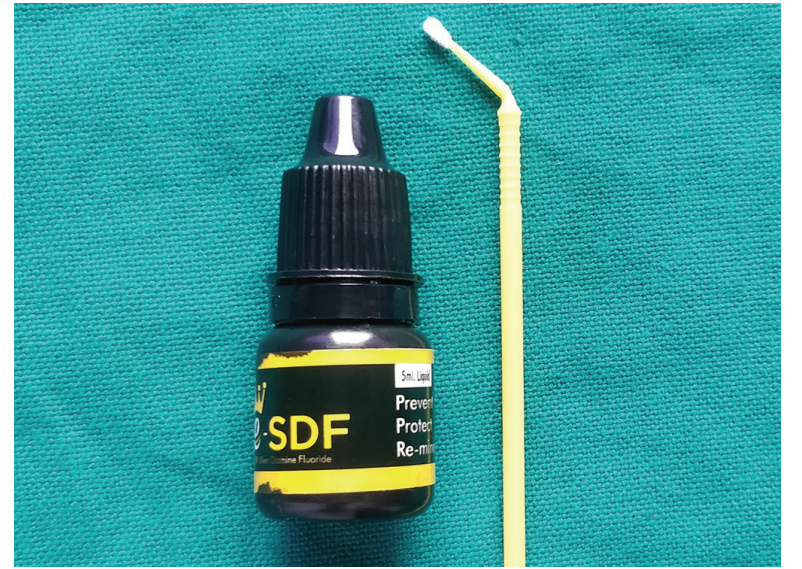

Fig. 1: Silver diamine fluoride bottle with a bent microbrush for SDF application

- With careful application using a microbrush, the intraoral and extraoral soft tissue exposure can be prevented. For a single complete appointment, not more than one drop of SDF should be used. One drop is sufficient to treat five to six teeth.

- Dry the lesion with a moderate stream of compressed air.

- Bend the microsponge brush (Fig. 1) for the application of SDF onto the tooth/carious lesion.

- To reduce additional liquid before application onto the teeth, dip the brush into SDF and pat against the side of the plastic dappen dish.

- Apply the SDF only onto the affected tooth surface.

- To minimize the systemic absorption, the excess SDF is removed with gauze, cotton roll, or pellet.

- Application time: if possible, at least 1 minute should be the application time with a gentle flow of compressed air to be applied until the SDF is dry. Three minutes' isolation of the treated area is required.

- Application frequency: biannual application is recommended for better results or to sustain the arrest as per many studies. The studies that had three times per year applications showed higher arrest rates.

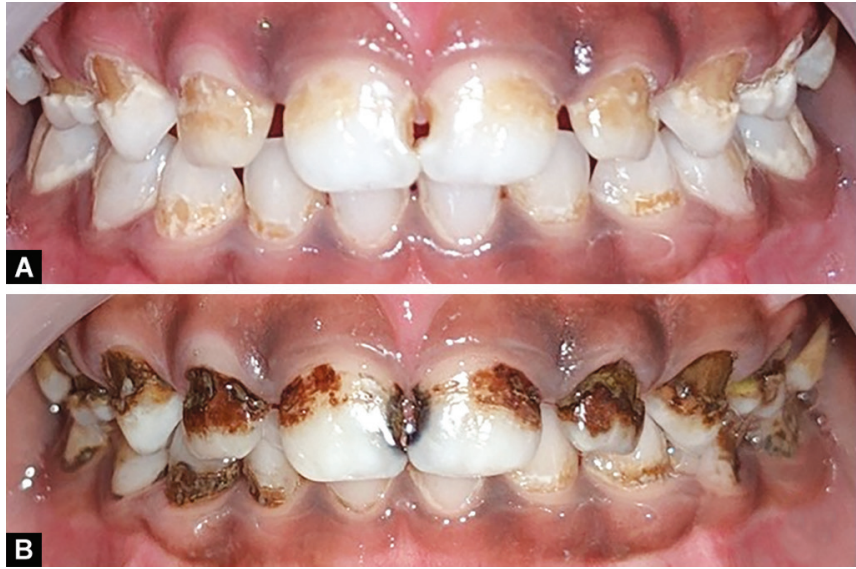

Figs 2A and B: Primary anterior teeth: (A) Before SDF; (B) After SDF application

\section{Postoperative Instructions and Follow-up}

No postoperative instructions are available from the manufacturers. However, several studies on SDF recommended 30 minutes to 1-hour restriction on consumption of food and drinks after SDF application. Follow-up is advised at 2-4 weeks after the initial SDF treatment to check the arrest of the treated lesions (hard and dark) (Fig. 2). Reapplication and additional SDF application at recall appointments are needed, according to the hardness and color of the cavitated lesion or evidence of lesion progression. ${ }^{13,26}$ The caries lesions can be restored after SDF treatment with resin modified glass ionomer or composites ${ }^{28}$ and is termed as SMART (Fig. 3). When lesions are not restored after SDF application, biannual reapplication is advised to increase the caries arrest rate.

\section{Mechanism of Action of SDF}

The SDF derives its effectiveness from the combination of silver nitrate and fluoride. There are three significant mechanisms in arresting or preventing dental caries, viz., the antibacterial action on cariogenic bacteria, the promotion of remineralization and inhibition of demineralization of enamel and dentine, and the reduction of dentine collagen matrix through collagenase inhibition. The SDF reacts with hydroxyapatite resulting in silver 

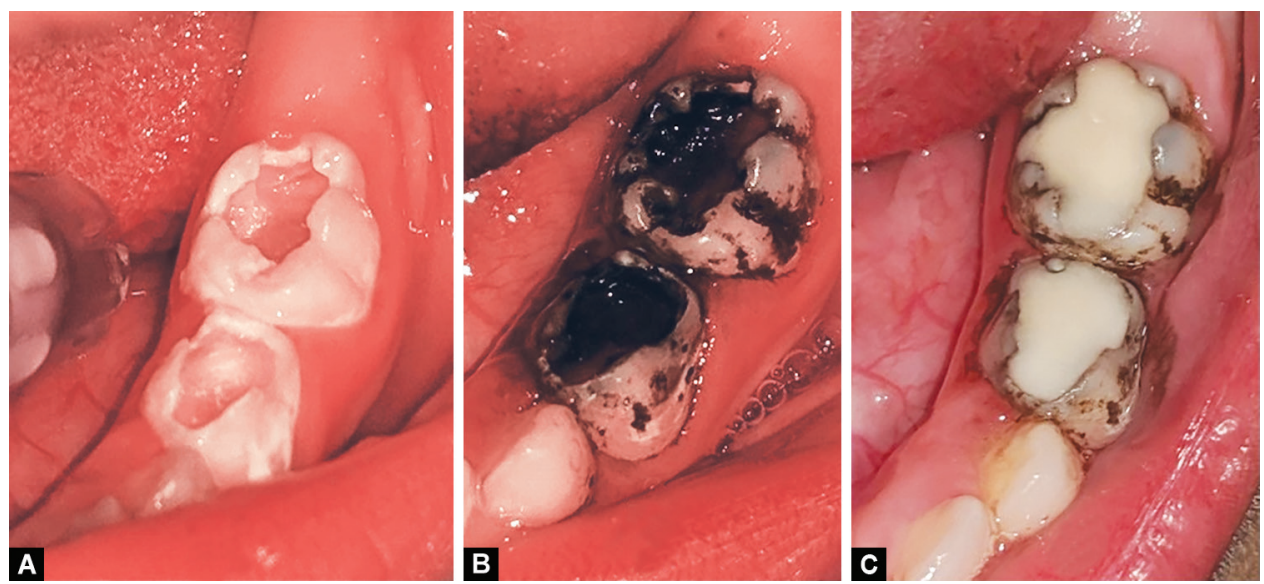

Figs 3A to C: Silver modified atraumatic restorative treatment (SMART) for \#74 and \#75: (A) Before SDF application; (B) After SDF application; (C) After GIC application

phosphate and calcium fluoride, which form a reservoir of fluoride and phosphate ions that promote remineralization. The silver ions penetrate the lesions and remain there to exert their influence (25-30 microns into the enamel, 200-300 microns into the dentin, and up to $2 \mathrm{~mm}$ into a deep carious lesion). The presence of silver compounds such as silver oxide and silver phosphate leads to the black staining of the carious lesions. ${ }^{12,13,31,32}$

\section{SDF in Caries Arrest of Primary Dentition}

The SDF panel of American Academy of Pediatric Dentistry (AAPD) backs the usage of $38 \%$ SDF in arresting the cavitated caries lesions of primary teeth for the comprehensive caries management program as a conditional recommendation with low-quality evidence. $^{26}$

Chibinski et al. in a systematic review showed that SDF is $89 \%$ more effective than other alternative treatments or placebo in arresting dental caries in primary dentition. ${ }^{33}$ They further reported a risk ratio (RR) of 1.66 [95\% confidence interval (CI)] comparing SDF with alternative treatments and RR of $2.54(95 \% \mathrm{Cl})$ for placebo or no treatment. In another systematic review and meta-analysis, Gao et al. stated that there was $81 \%$ arrestment $(95 \% \mathrm{Cl}, p<0.001)$ of active caries in primary dentition treated with SDF. ${ }^{10}$

Eight studies ${ }^{5,21,34-39}$ reported caries arrest with SDF application in children based on published literature in English for the last two decades (Table 2). Five studies reported the use of 38\% SDF for caries arrest $\mathrm{t}^{5,21,34,35,39}$ while three studies ${ }^{36-38}$ reported 30\% SDF. The researchers found that $38 \%$ of SDF application is most effective compared to a no treatment (negative control) or a placebo in the

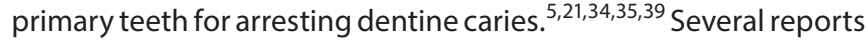
have noted that anterior teeth showed higher rates of arrest than the posterior teeth. ${ }^{35,37,39}$ Fung et al. ${ }^{39}$ report caries arrest by the type of primary tooth after semiannual application of 38\% SDF at 30 months. They reported an overall arrest of $75 \%$, with maximum benefit for lower anterior teeth (91.7\%) followed by upper anterior teeth $(85.6 \%)$, lower posterior teeth $(62.4 \%)$, and upper posterior teeth $(57.0 \%)$.

Besides, when the lesions have visible plaque or lesions are large, they showed a lesser probability of arrest. ${ }^{35,38,39}$ The difference in arrest rates between annual and semiannual applications was minor between the 24 months and 30 months for all the teeth; however, among children who received an annual application, those with visible plaque had lesser chances of arrested lesions. Fung et al. recommended that, for children with poor oral hygiene, caries arrest rate can be improved by increasing the frequency of application from annual to semiannual. ${ }^{39}$

\section{SDF in Caries Prevention of Primary Dentition}

Oliveira et al. ${ }^{11}$ in a systematic review and meta-analysis evaluated the effectiveness of SDF in preventing caries in primary dentition compared to placebo, fluoride varnish, or no treatment. They concluded that SDF appears to prevent caries effectively in the complete primary dentition. Contreras et al., ${ }^{40}$ in a systematic review, stated that children treated with SDF exhibited a significant reduction in inactive carious lesions. Rosenblatt et al. ${ }^{12}$ evaluated the potential of SDF for caries prevention using data from two trials. Llodra et al. ${ }^{21}$ found that $38 \%$ of SDF was utmost effective in preventing caries of the primary dentition and the authors found $80 \%$ reduction of new carious lesions in SDF ( 0.4 new lesions) compared to the water control group (1.1 new lesions) and the results were statistically significant over 36 months. Chu et al. ${ }^{34}$ who used only anterior maxillary teeth in their study of preschool children found that over 30 months, the SDF group showed the lesser mean number of new lesions (0.47) compared to the water control group (1.58).

\section{SDF for Caries Arrest and Prevention in First Permanent Molars}

Braga et al. ${ }^{41}$ noted that SDF demonstrated a quicker ability to arrest caries compared to the other techniques. Llodra et al. ${ }^{21}$ stated that the biannual application of SDF could arrest decay in the permanent first molars. Monse et al. ${ }^{42}$ reported that a one-time application of $38 \%$ SDF on the occlusal surfaces of permanent first molars of 6- to 8-year-old children was not an effective method to prevent the onset of new dentinal caries lesions in children. However, Llodra et al. and Liu et al. confirmed the prevention of new carious lesions in first permanent molars by using SDF. ${ }^{21,43}$

\section{Comparison between Primary Dentition and Permanent First Molars}

Llodra et al. stated that the SDF showed better efficacy to arrest decay in primary dentition than permanent first molars. The mean number of new carious surfaces observed in primary dentition during the study was 0.29 for the SDF group compared to 1.43 in controls. The mean of new carious surfaces for permanent first molars was 0.37 in the SDF group compared to 1.06 in controls. ${ }^{21}$ 


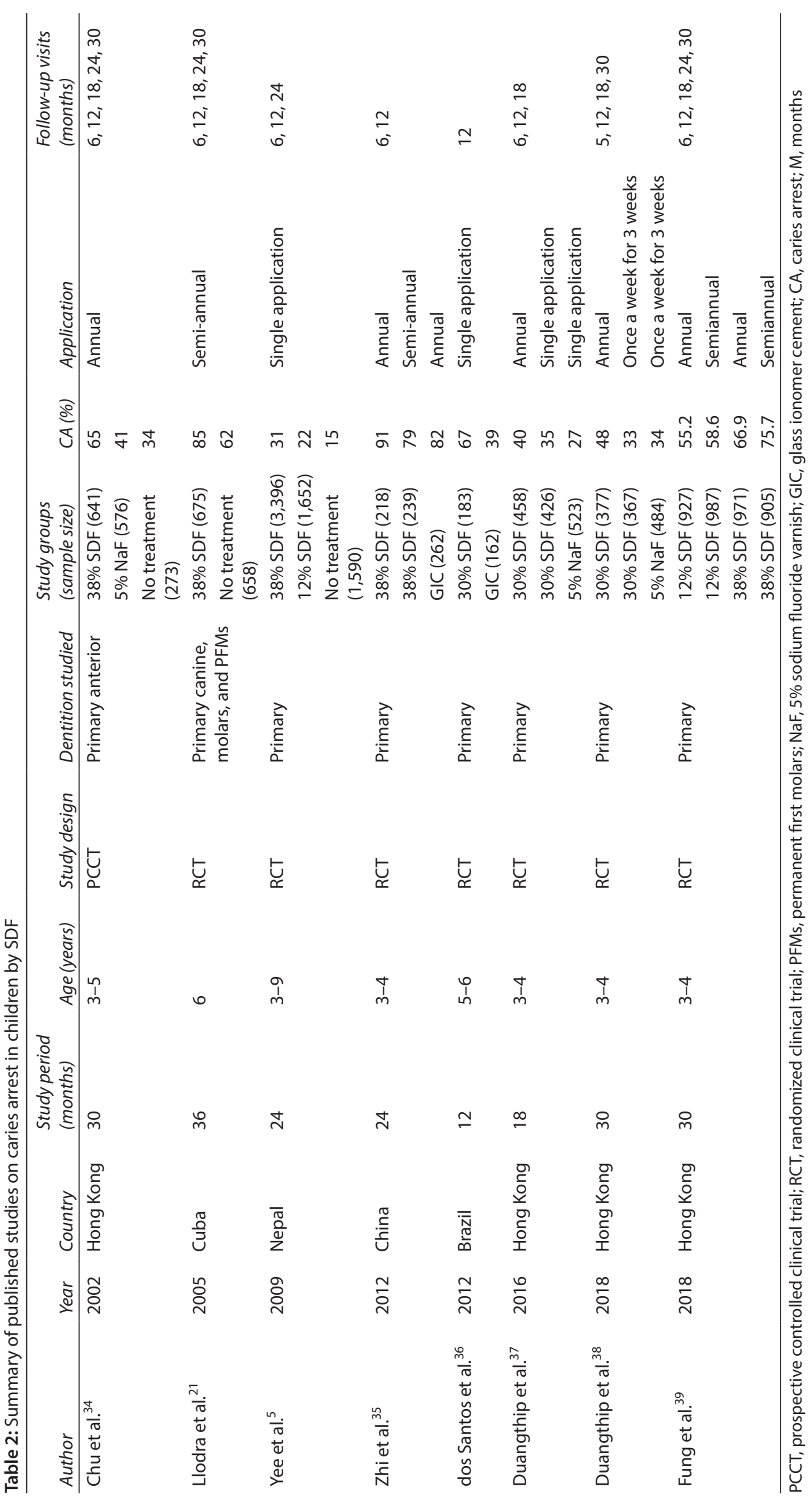




\section{Studies on SDF with Other Restorative Materials and Topical Fluoride Agents}

According to the available literature, the apparent initial bonding compatibility of SDF in vitro with glass ionomers and composite resins (CRs) gives SDF an important place in the pediatric dentist's inventory. ${ }^{44,45}$ Mei et al. evaluated the effect of 38\% SDF in preventing secondary caries in glass ionomer cement (GIC) and CR restorations and concluded that conditioning with $38 \%$ SDF could reduce secondary caries under GIC and CR restorations. ${ }^{46}$ dos Santos et al. ${ }^{36}$ compared GIC with $30 \%$ SDF with 12 months' follow-up, and SDF performed significantly better than GIC at 12 months, though this variance was not statistically significant.

McDonald and Sheiham ${ }^{47}$ clinically compared the application of stannous fluoride $\left(\mathrm{SnF}_{2}\right)$; application of $\mathrm{SnF}_{2}$ and $\mathrm{SDF}$; application of $\mathrm{SnF}_{2}$ and SDF followed by minimal cavity preparation and use of $\mathrm{CR}$; and minimal cavity preparation and CR only and no treatment. They concluded that caries progressed in only $5 \%$ of the SDF/SnF 2 group and $11 \%$ of the CR group.

Sodium fluoride (NaF) varnish is advised by many researchers for application onto the remaining sound teeth surfaces, once the SDF application is completed for the cavitated lesions. Chu et al. ${ }^{34}$ compared $38 \%$ SDF and fluoride varnish ( $5 \% \mathrm{NaF})$ with 30 months' follow-up and showed that SDF performed significantly better than fluoride varnish ( $5 \% \mathrm{NaF})$ at 18 months and 30 months of follow-up, though this variance was not statistically significant. According to Shah et al., SDF was more efficient in reducing the number of new carious surfaces, compared to NaF varnish and acidulated phosphate fluoride (APF) gel. ${ }^{48}$

\section{Points of Concern Related to SDF}

A primary concern is the child's fluoride dose of SDF. One drop $(0.05 \mathrm{~mL})$ of SDF, adequate to treat six teeth, contains $2.24 \mathrm{mg} F /$ dose and application of one drop of SDF would result in less amount of fluoride than that present in a $0.25 \mathrm{~mL}$ topical fluoride varnish. All the studies on SDF reported that there were no reported adverse systemic effects or deaths, though the long-term effects of repeated exposure to silver compounds are not known. ${ }^{13,22,26}$ However, for a cumulative effect of silver uptake and risk of silver poisoning to occur, a total lifetime silver exposure of $1 \mathrm{~g}$, corresponding to nearly 400 SDF applications is needed as per the U.S. Environmental Protection Agency. ${ }^{49}$

Another concern is the black discoloration ${ }^{10,11,34,40}$ in the arrested lesions disclosed after SDF application (Figs 2B and 3B). Parents and children should be informed that SDF application causes black or dark brown stain, as the soft infected dentin turns harder and development of a sclerotic black surface in the tooth. The adverse effects associated with any concentration of SDF application other than dental staining are metallic taste, pulpal and oral soft tissue irritation, ${ }^{17}$ development of small white reversible lesions in the oral mucosa, ${ }^{34}$ and gingivitis. ${ }^{19,24}$

Gotjamanos ${ }^{50}$ made a histological assessment of the dental pulps of carious primary teeth following a 3-56 months' treatment by the "atraumatic" technique using $40 \% \mathrm{AgF}$ to residual caries and restoration with GIC. A total of 50 of the 55 teeth exhibited a satisfactory pulpal response, with the existence of ample reparative dentine as well as an extensive odontoblast layer. He concluded that the biological acceptability of AgF for treating carious dentin could not be answered based on the histological status alone and raised questions regarding its clinical safety.

In the selected studies that used 30 and 38\% SDF, adverse events such as black stains and oral lesions were reported. ${ }^{10,34,40}$
The authors postulated that the low concentrations might reduce the harmful effects; nevertheless, these efficacies of low levels of SDF are lower compared with $38 \%$ SDF in arresting and or preventing caries in children.

Knight et al. ${ }^{44}$ reported that tooth discoloration could be reduced with the addition of potassium iodide (KI) before application to the SDF. Sayed et al. reported that glutathione biomolecule too affects reducing tooth discoloration after application of SDF, particularly on enamel and to a minor degree on dentin. ${ }^{51}$ However, the $\mathrm{Kl}$ is contraindicated in expectant women and during the first 6 months for lactating women due to concerns about developing thyroid of child, related to iodide overdose. ${ }^{13}$

\section{Other Considerations of SDF}

Besides the concerns mentioned above, it should be remembered that SDF will not treat or eradicate dental caries, but, it breaks or arrests the carious process of the surfaces that are treated. It may assist in remineralization of the lesion if the oral environment is conducive. Silver diamine fluoride does not restore tooth structure and function to normal. Besides this, when there is a considerable breakdown of a tooth, the occlusion and long-term clinical outcomes may deteriorate if restoration of form and function of the treated tooth is not undertaken. ${ }^{52}$

\section{Conclusion}

Silver diamine fluoride can be an effective, inexpensive, and sustainable option for high-risk children and adolescents across all the age groups in arresting dentin caries. It is an excellent antimicrobial agent in the prevention of biofilm formation and dental caries. Additional indications include individuals who cannot endure conventional modalities of restorative treatment, individuals who cannot access dental care facilities, and those with special health-care needs. Evidence suggests that twice a year application of SDF is useful in arresting or preventing dental caries compared to placebo or other alternative modalities. Sustained use of SDF until the tooth is restored or exfoliates is advised.

Further research is recommended to determine the status of the arrested lesions if treatment is withdrawn after $2-3$ years along with the long-term safety of the SDF on repeated usage. Studies are also recommended to assess the efficacy of SDF related to the prevention of dental caries in the permanent molars.

\section{ACKNoWledgments}

The authors would like to acknowledge the editorial board of the JSAAPD for giving the opportunity for this invited review and Dr Kumar Raja Gaddam, Little Mouth, Vijayawada, for providing the clinical photographs.

\section{References}

1. Pitts N, Amaechi B, Niederman R, et.al. Global oral health inequalities: dental caries task group-research agenda. Adv Dent Res 2011;23(2):211-220. DOI: 10.1177/0022034511402016.

2. dos Santos AP, Nadanovsky P, de Oliveira BH. A systematic review and meta-analysis of the effects of fluoride toothpastes on the prevention of dental caries in the primary dentition of preschool children. Community Dent Oral Epidemiol 2013;41(1):1-12. DOI: 10.1111/j.1600-0528.2012.00708.x.

3. Duangthip D, Ming J, Chu CH, et al. Nonsurgical treatment of dentin caries in preschool children - systematic review. BMC Oral Health 2015;15:44. DOI: 10.1186/s12903-015-0033-7. 
4. Dye BA, Hsu KL, Afful J. Prevalence and measurement of dental caries in young children. Pediatr Dent 2015;37(3):200-216.

5. Yee R, Holmgren C, Mulder J, et al. Efficacy of silver diamine fluoride for arresting caries treatment. J Dent Res 2009;88(7):644-647. DOI: 10.1177/0022034509338671.

6. Meyer BD, Lee JY, Lampiris LN, et al. "They Told Me to Take Him Somewhere Else:" caregivers' experiences seeking emergency dental care for their children. Pediatr Dent 2017;39(3):209-214.

7. Peng JJ, Botelho MG, Matinlinna JP. Silver compounds used in dentistry for caries management: a review. J Dent 2012;40(7):531-541. DOI: 10.1016/j.jdent.2012.03.009.

8. Frencken JE, Peters MC, Manton DJ, et al. Minimal intervention dentistry for managing dental caries - a review: report of a FDI task group. DOI: Int Dent J 2012;62(5):223-243. DOI: 10.1111/idj.12007.

9. Lehmann M, Veitz-Keenan A, Matthews AG, et. al. Dentin caries activity in early occlusal lesions selected to receive operative treatment: findings from the practitioners engaged in applied research and learning (PEARL) network. J Am Dent Assoc 2012;143(4):377-385. DOI: 10.14219/jada.archive.2012.0180.

10. Gao SS, Zhang S, Mei ML, et al. Caries remineralisation and arresting effect in children by professionally applied fluoride treatment-a systematic review. BMC Oral Health 2016;16:12. DOI: 10.1186/s12903016-0171-6.

11. Oliveira BH, Rajendra A, Veitz-Keenan A, et al. The effect of silver diamine fluoride in preventing caries in the primary dentition: a systematic review and meta-analysis. Caries Res 2019;53(1):24-32. DOI: $10.1159 / 000488686$.

12. Rosenblatt A, Stamford TC, Niederman R. Silver diamine fluoride: a caries "silver-fluoride bullet". J Dent Res 2009;88(2):116-125. DOI: 10.1177/0022034508329406.

13. Horst JA, Ellenikiotis H, Milgrom PL. UCSF protocol for caries arrest using silver diamine fluoride: rationale, indications, and consent. J Calif Dent Assoc 2016;44(1):16-28.

14. Crystal YO, Niederman R. Evidence-based dentistry update on silver diamine fluoride. Dent Clin North Am 2019;63(1):45-68. DOI: 10.1016/ j.cden.2018.08.011.

15. Russell AD, Hugo WB. Antimicrobial activity and action of silver. Prog Med Chem 1994;31:351-370.

16. Stebbins EA. What value has argenti nitras as a therapeutic agent in dentistry? Int Dent J 1891;12:661-670.

17. Howe PR. A method of sterilizing and at the same time impregnating with a metal affected dentinal tissue. Dent Cosmos 1917;59(9): 891-904

18. Craig GG, Powell KR, Cooper MH. Caries progression in primary molars: 24-month results from a minimal treatment programme. Community Dent Oral Epidemiol 1981;9(6):260-265. DOI: 10.1111/ j.1600-0528.1981.tb00342.x.

19. Nishino M, Yoshida S, Sobue $S$, et al. Effect of topically applied ammoniacal silver fluoride on dental caries in children. J Osaka Univ Dent Sch 1969;9:149-155.

20. Yamaga R, Nishino M, Yoshida S, et al. Diammine silver fluoride and its clinical application. J Osaka Univ Dent Sch 1972;12:1-20.

21. Llodra JC, Rodriguez A, Ferrer B, et al. Efficacy of silver diamine fluoride for caries reduction in primary teeth and first permanent molars of schoolchildren: 36-month clinical trial. J Dent Res 2005;84(8):721-724. DOI: $10.1177 / 154405910508400807$

22. Burgess JO, Vaghela PM. Silver diamine fluoride: a successful anticarious solution with limits. Adv Dent Res 2018;29(1):131-134. DOI: $10.1177 / 0022034517740123$.

23. Mei ML, Chu CH, Lo EC, et al. Fluoride and silver concentrations of silver diammine fluoride solutions for dental use. Int J Paediatr Dent 2013;23(4):279-285. DOI: 10.1111/ipd.12005.

24. Mei ML, Lo EC, Chu CH. Clinical use of silver diamine fluoride in dental treatment. Compend Contin Educ Dent 2016;37(2):93-98.

25. eSDF-38\% silver diamine fluoride. URL: http://kids-e-dental.com/ Products/SDF last accessed on 22-08-2019 at 11-00 AM.

26. Crystal YO, Marghalani AA, Ureles SD, et. al. Use of silver diamine fluoride for dental caries management in children and adolescents, including those with special health care needs. Pediatr Dent 2017;39(5):135-145.

27. Slayton RL, Urquhart O, Araujo MWB, et al. Evidence-based clinical practice guideline on nonrestorative treatments for carious lesions: a report from the American Dental Association. J Am Dent Assoc 2018;149(10):837-849. DOI: 10.1016/j.adaj.2018.07.002. e19.

28. MacLean J. Clinical uses for silver diamine fluoride - oral health group. Available on URL: https://www.oralhealthgroup.com/features/ clinical-uses-for-silver-diamine-fluoride/, last accessed on 28th July 2019 at 11.00 am IST.

29. $\mathrm{Chu} \mathrm{CH}$, Lo EC. Promoting caries arrest in children with silver diamine fluoride: a review. Oral Health Prev Dent 2008;6(4):315-321.

30. Burgette JM, Weintraub JA, Birken SA, et al. Development of a silver diamine fluoride protocol in safety net dental settings. J Dent Child (Chic) 2019;86(1):32-39.

31. Suzuki T, Nishida M, Sobue S, et al. Effects of diammine silver fluoride on tooth enamel. J Osaka Univ Dent Sch 1974;14:61-72.

32. Zhao IS, Gao SS, Hiraishi N, et. al. Mechanisms of silver diamine fluoride on arresting caries: a literature review. Int Dent J 2018;68(2):67-76. DOI: 10.1111/idj.12320.

33. Chibinski AC, Wambier LM, Feltrin J, et al. Silver diamine fluoride has efficacy in controlling caries progression in primary teeth: a systematic review and meta-analysis. Caries Res 2017;51(5):527-541. DOI: 10.1159/000478668.

34. Chu CH, Lo EC, Lin HC. Effectiveness of silver diamine fluoride and sodium fluoride varnish in arresting dentin caries in Chinese preschool children. J Dent Res 2002;81(11):767-770. DOI: 10.1177/0810767.

35. Zhi QH, Lo EC, Lin HC. Randomized clinical trial on effectiveness of silver diamine fluoride and glass ionomer in arresting dentine caries in preschool children. J Dent 2012;40(11):962-967. DOI: 10.1016/ j.jdent.2012.08.002.

36. dos Santos Jr VE, de Vasconcelos FM, Ribeiro AG, et al. Paradigm shift in the effective treatment of caries in schoolchildren at risk. Int Dent J 2012;62(1):47-51. DOI: 10.1111/j.1875-595X.2011.00088.x.

37. Duangthip $\mathrm{D}, \mathrm{Chu} \mathrm{CH}$, Lo ECM. A randomized clinical trial on arresting dentine caries in preschool children by topical fluorides-18 month results. J Dent 2016;44:57-63. DOI: 10.1016/j.jdent.2015.05.006.

38. Duangthip $\mathrm{D}$, Wong $\mathrm{MCM}, \mathrm{Chu} \mathrm{CH}$, et al. Caries arrest by topical fluorides in preschool children: 30-month results. J Dent 2018;70: 74-79. DOI: 10.1016/j.jdent.2017.12.013.

39. Fung MHT, Duangthip D, Wong MCM, et al. Randomized clinical trial of $12 \%$ and $38 \%$ silver diamine fluoride treatment. J Dent Res 2018;97(2):171-178. DOI: 10.1177/0022034517728496.

40. Contreras V, Toro MJ, Elias-Boneta AR, et al. Effectiveness of silver diamine fluoride in caries prevention and arrest: a systematic literature review. Gen Dent 2017;65(3):22-29.

41. Braga MM, Mendes FM, De Benedetto MS, et al. Effect of silver diamine fluoride on incipient caries lesions in erupting permanent first molars: a pilot study. J Dent Child (Chic) 2009;76(1):28-33.

42. Monse B, Heinrich-Weltzien R, Mulder J, et al. Caries preventive efficacy of silver diammine fluoride (SDF) and ART sealants in a schoolbased daily fluoride toothbrushing program in the Philippines. BMC Oral Health 2012;12:52. DOI: 10.1186/1472-6831-12-52.

43. Liu BY, Lo EC, Chu CH, et al. Randomized trial on fluorides and sealants for fissure caries prevention. J Dent Res 2012;91(8):753-758. DOI: 10.1177/0022034512452278.

44. Knight GM, Mclntyre JM. The effect of silver fluoride and potassium iodide on the bond strength of autocure glass ionomer cement to dentine. Aus Dent J 2006;51(1):42-45. DOI: 10.1111/j.1834-7819.2006. tb00399.x

45. Yamaga M, Koide T, Hieda T. Adhesiveness of glass ionomer cement containing tannin-fluoride preparation (HY agent) to dentin-an evaluation of adding various ratios of $\mathrm{HY}$ agent and combination with application diamine silver fluoride. Dent Mater J 1993;12(1):36-44. DOI: $10.4012 / \mathrm{dmj} .12 .36$.

46. Mei ML, Zhao IS, Ito L, et al. Prevention of secondary caries by silver diamine fluoride. Int Dent J 2016;66(2):71-77. DOI: 10.1111/idj. 12207. 
47. McDonald SP, Sheiham A. A clinical comparison of non-traumatic methods of treating dental caries. Int Dent J 1994;44(5):465-470.

48. Shah SG, Bhaskar V, Chawla S, et al. Efficacy of silver diamine fluoride as a topical fluoride agent compared to fluoride varnish and acidulated phosphate fluoride gel: an in vivo study. J Pediatr Dent 2014;2:5-12. DOI: 10.4103/2321-6646.130376.

49. Vasquez E, Zegarra G, Chirinos E, et. al. Short term serum pharmacokinetics of diammine silver fluoride after oral application. BMC Oral Health 2012;12:60. DOI: 10.1186/1472-6831-12-60.
50. Gotjamanos T. Pulp response in primary teeth with deep residual caries treated with silver fluoride and glass ionomer cement. Aust Dent J 1996;41(5):328-334. DOI: 10.1111/j.1834-7819.1996.tb03142.x.

51. Sayed M, Matsui N, Hiraishi N, et al. Effect of glutathione bio-molecule on tooth discoloration associated with silver diammine fluoride. Int J Mol Sci 2018;19(5):E1322. DOI: 10.3390/ijms19051322.

52. McConnachie I, Friedman CS, Abrams SA. Silver diamine fluoride: a new tool against caries or a game changer? J Ontario Dent Assoc 2018;95:36-40. 